\title{
Characteristics of symptom burden in atrial fibrillation with concomitant heart failure
}

\author{
Ran Heo ${ }^{1 \dagger}$, Myung-Jin Cha ${ }^{2 \dagger}$, Tae-Hoon Kim ${ }^{3}$, Jung Myung Lee ${ }^{4}$, Junbeom Park ${ }^{5}$, Hyung Wook Park ${ }^{6}$, \\ Ki-Woon Kang ${ }^{7}$, Jaemin Shim ${ }^{8}$, Jae-Sun Uhm³ ${ }^{3}$ Jun Kim ${ }^{9}$, Jin-Bae Kim³ ${ }^{3}$ Changsoo Kim ${ }^{10}$, Young Soo Lee ${ }^{11}$, \\ Eue-Keun $\mathrm{Choi}^{2}$, Boyoung Joung ${ }^{3^{*}}$ and Jin-Kyu Park ${ }^{1 *}$ (D)
}

\begin{abstract}
Background: Symptom burden is an important factor in determining the treatment of atrial fibrillation (AF). AF is frequently accompanied by heart failure (HF). This study investigated the characteristics of AF symptoms with concomitant HF.

Methods: A total of 4885 patients with AF were consecutively enrolled through a prospective observational registry (the Comparison Study of Drugs for Symptom Control and Complication Prevention of Atrial Fibrillation [CODE-AF] registry). Clinically diagnosed HF was divided into three categories (preserved, mid-range, and reduced ejection fraction [EF]). Symptom severity was assessed using the European Heart Rhythm Association (EHRA) classification.

Results: The presence of AF-related symptoms was comparable irrespective of concomitant HF. Patients with HF with reduced EF demonstrated severe (EHRA classes 3 and 4 ) and atypical symptoms. HF with preserved EF was also associated with atypical symptoms. Female sex and AF type were associated with the presence of symptoms in AF without $\mathrm{HF}$, and non-maintenance of sinus rhythm and increased left atrial pressure $\left(E / e^{\prime} \geq 15\right)$ were factors related to the presence of symptoms in AF with HF.

Conclusion: AF with concomitant HF presented with more severe and atypical symptoms than AF without HF. Maintaining the sinus rhythm and reducing the Ele' ratio are important factors for reducing symptoms in AF with concomitant HF.
\end{abstract}

Keywords: Symptom burden, Atrial fibrillation, Heart failure

\section{Introduction}

Atrial fibrillation (AF) is associated with various symptoms. Although palpitations are the most typical symptom of AF, atypical symptoms are frequently encountered in clinical situations [1]. Severe symptoms, such as

\footnotetext{
*Correspondence: cby6908@yuhs.ac; cardiohy@hanyang.ac.kr

${ }^{\dagger}$ Ran Heo and Myung-Jin Cha have contributed equally to this work.

${ }^{1}$ Department of Cardiology, Hanyang University Medical Center, Hanyang

University Seoul Hospital, 222-1 Wangsimri Road, Seongdong-gu,

Seoul 04763, Republic of Korea

${ }^{3}$ Division of Cardiology, Department of Internal Medicine, Severance

Cardiovascular Hospital, Yonsei University College of Medicine, Seoul, Republic of Korea

Full list of author information is available at the end of the article
}

dyspnea or palpitations, can decrease the quality of life and increase the risk of hospitalization [2]. Furthermore, the presenting symptoms have important prognostic implications. AF patients with non-palpitation symptoms have higher rates of stroke and mortality than those with a more typical presentation [1]. AF is often concomitant with heart failure (HF), with each condition predisposing the patient to the other [3]. Patients with HF also experience shortness of breath, dyspnea on exertion, and fatigue, all of which affect quality of life. AF is also commonly associated with dyspnea on exertion followed by palpitations [2]. Therefore, when AF is present

c) The Author(s) 2020. This article is licensed under a Creative Commons Attribution 4.0 International License, which permits use, sharing, adaptation, distribution and reproduction in any medium or format, as long as you give appropriate credit to the original author(s) and the source, provide a link to the Creative Commons licence, and indicate if changes were made. The images or other third party material in this article are included in the article's Creative Commons licence, unless indicated otherwise in a credit line to the material. If material is not included in the article's Creative Commons licence and your intended use is not permitted by statutory regulation or exceeds the permitted use, you will need to obtain permission directly from the copyright holder. To view a copy of this licence, visit http://creativeco mmons.org/licenses/by/4.0/. 
in combination with HF, their symptoms can be mixed, confused, and affected by each other.

Rhythm control via antiarrhythmic medication can be used to treat AF patients, and catheter ablation is a wellestablished treatment for symptomatic AF [4]. Recently, catheter ablation for AF in patients with HF has been shown to be beneficial in reducing the burden of AF and improving the left ventricular (LV) ejection fraction (EF), and it is similarly effective regardless of the presence of systolic dysfunction [5, 6]. In clinical situations, the presence of symptoms plays a major role in determining the proper treatment strategy for AF, with catheter ablation recommended mainly for symptomatic patients [4]. Therefore, evaluating the symptoms in AF with concomitant HF is important for the management of AF patients. To the best of our knowledge, no large-scale data have yet been evaluated in that way. Therefore, we investigated the characteristic differences in symptom burden and related factors in AF with concomitant HF.

\section{Methods \\ Database}

The data we analyzed for this study were from the prospective Comparison Study of Drugs for Symptom Control and Complication Prevention of AF (CODE-AF) registry. The CODE-AF is a prospective, multicenter, observational study of patients older than 18 years with AF. Patients were enrolled in ten tertiary centers encompassing all geographical regions of Korea. The study design and centers have been described previously [7]. The study was approved by the ethics committee of each center, and all patients provided informed consent for their inclusion. This study was registered at ClinicalTrials.gov (NCT02786095). The CODE-AF registry is an ongoing enrollment database. The first database for analysis was released in May 2017 and included patients from June 2016 to April 2017. The data entered at each center were audited regularly, and the database used for this analysis had completed the data cleaning process. Patient data collection was performed according to the same criteria. The collected data were registered in the Web-based clinical research management system iCreat (Internet-based Clinical Research and Trial Management System, http://icreat.nih.go.kr) provided by the Korean government.

\section{Study population}

A total of 6265 patients enrolled between June 2016 and April 2017 were included in the initial analysis. Patients missing the following data were excluded from this study: symptom descriptions $(n=232)$, recent echocardiography data $(n=968)$, available clinical history about the presence of HF $(n=55)$, or appropriate clinical data $(n=125)$. The final study group included 4885 patients with AF. Among them, 563 (11.5\%) were also diagnosed with HF by each clinician of tertiary centers according to HF guideline for the diagnosis [8].

\section{Definition of AF-related symptoms}

Patient symptoms were collected through questionnaires, and clinical research coordinators at each center checked the responses. When patients were enrolled, they were asked about symptoms such as chest pain, dizziness, fainting, irregular pulse, palpitations, shortness of breath, sweating, and tiredness. If the patient reported at least one symptom, he or she was considered to be symptomatic. Patients experiencing palpitations with or without other concomitant symptoms were considered to offer a "typical presentation." Patients with symptoms but without palpitations were considered to offer an "atypical presentation" using the same method as previous study [1]. Symptoms related to AF were classified into three grades according to their degree of influence on daily activity, based on the European Heart Rhythm Association (EHRA) symptom scale [9]. EHRA class 1 indicates no symptoms; class 2 includes mild or moderate symptoms that leave normal daily activities unaffected; and classes 3-4 include severe to disabling symptoms, with normal daily activities affected or discontinued.

\section{Echocardiography}

Transthoracic echocardiography (2D, M-mode, pulsedwave, continuous-wave, and color tissue Doppler) was performed before the enrollment of each patient. Echocardiographic data were obtained by trained research echocardiographers at each center and measured according to published guidelines [10]. The left ventricular EF was reported as a percentage. HF patients were categorized as having reduced $(<40 \%)$, mid-range $(40-49 \%)$, or preserved $(\geq 50 \%)$ EF (HFrEF, HFmrEF, and HFpEF, respectively). The left atrial diameter was measured from the parasternal view. The ratio between the early mitral inflow velocity and mitral annular early diastolic velocity $\left(E / e^{\prime}\right)$ was obtained. An $E / e^{\prime}$ of 15 or more was considered to indicate increased left atrial (LA) pressure.

\section{Statistical analysis}

Baseline characteristics were compared according to the presence of HF. Continuous variables are presented as the mean \pm standard deviation and were compared using independent $\mathrm{t}$-tests. Categorical variables were compared by Fisher's exact test or the $\chi^{2}$ test. A multivariate binary logistic regression analysis was used to determine the effect of HF on AF symptoms. The covariates were age, sex, CHADS-VASc score $\geq 2$, stage of chronic kidney disease $\geq 3$, smoking status, alcohol consumption, 
AF pattern, blood pressure (BP), and heart rate (HR). Additionally, a multivariate analysis with a forward variable selection process was performed to document factors associated with the presence of AF symptoms in AF patients with and without concomitant HF. We included parameters of electrocardiography (presence of sinus rhythm, QRS duration, and QT interval) and echocardiography (EF, size of the left atrium, and $E / e^{\prime}$ ratio) as covariates. Two-tailed tests were used to determine significance. A $p$ value $<0.05$ was considered statistically significant. Statistical analyses were performed using the SPSS Statistics 21.0 software package (IBM SPSS, New York, USA).

\section{Results}

\section{General characteristics of AF patients with HF}

Table 1 lists the general characteristics of patients with AF according to the presence or absence of HF. AF patients with HF were older and had greater ratios of CHADS-VASc score $\geq 2$ and HAS-BLED score $\geq 3$. These patients were more likely to have diabetes mellitus, a history of myocardial infarction, peripheral artery disease, or chronic kidney disease. Current alcohol consumption was less frequent. However, patients with AF and HFrEF were male dominant, and current alcohol consumption or smoking was more frequent than those without HF (Additional file 1: Table S1). They had lower systolic and diastolic BP and higher HR.

In AF patients with $\mathrm{HF}$, paroxysmal AF was less frequent than in AF patients without HF (47.1 vs. $66.0 \%$, $p<0.001)$. The average $\mathrm{EF}$ was $47.7 \pm 13.6 \%$ and the ratio of HFrEF, HFmrEF, and HFpEF was $29.0 \%, 27.0 \%$, and $44.0 \%$, respectively. Patients with both AF and HF demonstrated a larger LA and increased $E / e^{\prime}$ ratio. They showed less frequent sinus rhythm maintenance and a longer QRS duration and QT interval than AF patients without HF.

\section{Treatment strategies according to presence of $\mathrm{HF}$}

The prescription pattern differed significantly between the groups with and without HF (Table 2). Angiotensin receptor blockers or angiotensin-converting enzyme inhibitors, beta blockers, and digoxin were prescribed more frequently to AF patients with HF than to patients without HF. However, the use of non-dihydropyridine calcium channel blockers was less frequent in patients with HF. Regarding the AF treatment strategy, rhythm control strategies were used less frequently in patients with HF than in patients without. Among the non-pharmacological AF treatments, ablation was less frequent in the HF group, but electrical cardioversion was more
Table 1 General characteristics according to the presence of heart failure in atrial fibrillation

\begin{tabular}{|c|c|c|c|}
\hline $\begin{array}{l}\text { No. of patients } \\
n=4885\end{array}$ & $\begin{array}{l}\text { No HF } \\
n=4322\end{array}$ & $\begin{array}{l}\text { HF } \\
n=563\end{array}$ & $p$ value \\
\hline Age, years & $67.2 \pm 10.7$ & $69.3 \pm 11.0$ & $<0.001$ \\
\hline Age $\geq 65$ & $2686(62.1 \%)$ & $388(68.9 \%)$ & 0.002 \\
\hline Sex & & & 0.603 \\
\hline Female & $1579(36.5 \%)$ & $212(37.7 \%)$ & \\
\hline Male & $2743(63.5 \%)$ & $351(62.3 \%)$ & \\
\hline BMI $\left(\mathrm{kg} / \mathrm{m}^{2}\right)$ & $24.7 \pm 3.4$ & $24.6 \pm 3.7$ & 0.503 \\
\hline $\mathrm{CHA}_{2} \mathrm{DS}_{2}$-VASc score $\geq 2$ & 3141 (72.7\%) & $525(93.3 \%)$ & $<0.001$ \\
\hline HAS-BLED score $\geq 3$ & $1046(24.2 \%)$ & $161(28.6 \%)$ & 0.025 \\
\hline Hypertension & $2964(68.6 \%)$ & $401(71.2 \%)$ & 0.209 \\
\hline Diabetes mellitus & $1089(25.2 \%)$ & $171(30.4 \%)$ & 0.009 \\
\hline Dyslipidemia & $1590(36.8 \%)$ & $205(36.4 \%)$ & 0.553 \\
\hline Myocardial infarction & $93(2.2 \%)$ & $44(7.8 \%)$ & $<0.001^{*}$ \\
\hline Stroke history & $719(16.6 \%)$ & $109(19.4 \%)$ & 0.107 \\
\hline Cancer & $490(11.3 \%)$ & $54(9.6 \%)$ & 0.227 \\
\hline PAD & $212(4.9 \%)$ & $53(9.4 \%)$ & 0.002 \\
\hline CKD $(e G F R<60)$ & $434(10.0 \%)$ & $85(15.1 \%)$ & $<0.001$ \\
\hline ESRD on dialysis & $75(1.6 \%)$ & $6(1.1 \%)$ & $0.294^{*}$ \\
\hline Permanent pacemaker & $278(6.4 \%)$ & $48(8.5 \%)$ & 0.072 \\
\hline ICD & $17(0.4 \%)$ & $33(5.9 \%)$ & $<0.001^{*}$ \\
\hline Alcohol drinking & & & 0.045 \\
\hline Current & $945(22.0 \%)$ & $106(18.9 \%)$ & \\
\hline Social & $340(7.9 \%)$ & $34(6.0 \%)$ & \\
\hline Never & $3014(70.1 \%)$ & $422(75.1 \%)$ & \\
\hline Smoking & & & 0.027 \\
\hline Current & $363(8.4 \%)$ & $64(11.4 \%)$ & \\
\hline Former & $1002(23.2 \%)$ & $140(24.9 \%)$ & \\
\hline Never & $2957(68.4 \%)$ & $359(63.8 \%)$ & \\
\hline Systolic blood pressure (mmHg) & $122.2 \pm 14.7$ & $120.2 \pm 16.6$ & 0.002 \\
\hline Diastolic blood pressure $(\mathrm{mmHg})$ & $74.6 \pm 11.1$ & $73.0 \pm 12.6$ & 0.002 \\
\hline Heart rate (bpm) & $74.7 \pm 15.6$ & $78.5 \pm 17.9$ & $<0.001$ \\
\hline AF pattern & & & $<0.001$ \\
\hline Paroxysmal & $2851(66.0 \%)$ & $265(47.1 \%)$ & \\
\hline Persistent & $1290(29.8 \%)$ & $240(42.6 \%)$ & \\
\hline Permanent & $181(4.2 \%)$ & $58(10.3 \%)$ & \\
\hline AF documentation & & & 0.840 \\
\hline Newly diagnosed & $206(4.8 \%)$ & $26(4.6 \%)$ & \\
\hline Within 3 months & $353(8.2 \%)$ & $50(8.9 \%)$ & \\
\hline Above 3 months & $3763(87.1 \%)$ & $487(86.5 \%)$ & \\
\hline \multicolumn{4}{|l|}{ Echocardiography } \\
\hline $\mathrm{EF}(\%)$ & $63.6 \pm 6.2$ & $47.7 \pm 13.6$ & $<0.001$ \\
\hline$<40$ & - & $163(29.0 \%)$ & \\
\hline $40-50$ & - & $152(27.0 \%)$ & \\
\hline$>50$ & $4322(100 \%)$ & $248(44.0 \%)$ & \\
\hline LA size $(\mathrm{mm})$ & $43.3 \pm 7.7$ & $47.3 \pm 8.8$ & $<0.001$ \\
\hline Ele $e^{\prime}$ ratio & $11.4 \pm 5.0$ & $14.2 \pm 6.6$ & $<0.001$ \\
\hline \multicolumn{4}{|l|}{ Electrocardiography } \\
\hline Sinus rhythm & $2236(51.8 \%)$ & $187(33.2 \%)$ & $<0.001$ \\
\hline QRS duration (ms) & $98.6 \pm 19.3$ & $103.6 \pm 24.7$ & $<0.001$ \\
\hline
\end{tabular}


Table 1 (continued)

\begin{tabular}{llll}
\hline $\begin{array}{l}\text { No. of patients } \\
\boldsymbol{n}=\mathbf{4 8 8 5}\end{array}$ & $\begin{array}{l}\text { No HF } \\
\boldsymbol{n}=\mathbf{4 3 2 2}\end{array}$ & $\begin{array}{l}\text { HF } \\
\boldsymbol{n}=\mathbf{5 6 3}\end{array}$ & $\boldsymbol{p}$ value \\
\hline Corrected QT interval (ms) & $439.7 \pm 32.9$ & $452.0 \pm 40.0$ & $<0.001$
\end{tabular}

Numerical variables are expressed as mean \pm standard deviation, and categorical variables are represented as the absolute value with the percentage in parentheses

Fisher's exact test $\left.{ }^{*}\right)$

$A F$ atrial fibrillation, $B M I$ body mass index, $C K D$ chronic kidney disease, $E F$ ejection fraction, ESRD end-stage renal disease, ICD implantable cardiac defibrillator, $L A$ left atrium, $P A D$ peripheral artery disease

Table 2 Treatment strategies according to the presence of heart failure

\begin{tabular}{|c|c|c|c|}
\hline $\begin{array}{l}\text { No. of patients } \\
n=4885\end{array}$ & $\begin{array}{l}\text { No HF } \\
n=4322\end{array}$ & $\begin{array}{l}\text { HF } \\
n=563\end{array}$ & $p$ value \\
\hline \multicolumn{4}{|l|}{ Pharmacologic treatment } \\
\hline ARB or $A C E i$ & $1627(37.7 \%)$ & $389(69.5 \%)$ & $<0.001$ \\
\hline Beta blocker & $2163(50.1 \%)$ & $378(67.5 \%)$ & $<0.001$ \\
\hline Non-DHP CCB & $1322(30.6 \%)$ & $136(24.3 \%)$ & 0.002 \\
\hline Digoxin & $235(5.4 \%)$ & $104(18.6 \%)$ & $<0.001$ \\
\hline Statin & $1501(34.7 \%)$ & $241(43.0 \%)$ & $<0.001$ \\
\hline AF treatment strategy & & & $<0.001$ \\
\hline Rhythm control & $2129(49.3 \%)$ & $201(35.7 \%)$ & \\
\hline Rate control only & $1564(36.2 \%)$ & $317(56.3 \%)$ & \\
\hline None & $629(14.6 \%)$ & $45(8.0 \%)$ & \\
\hline \multicolumn{4}{|c|}{$\begin{array}{l}\text { Non-pharmacological AF treat- } \\
\text { ment }\end{array}$} \\
\hline Catheter ablation & 809 (18.7\%) & $83(14.8 \%)$ & 0.023 \\
\hline Electrical cardioversion & $748(17.3 \%)$ & $131(23.3 \%)$ & 0.001 \\
\hline \multicolumn{4}{|l|}{ Stroke prevention } \\
\hline $\mathrm{CHA}_{2} \mathrm{DS}_{2}-\mathrm{VASC} \leq 1$ & & & $0.095^{*}$ \\
\hline None & $797(67.5 \%)$ & $20(52.6 \%)$ & \\
\hline Anti-platelet agents & $22(1.0 \%)$ & $0(0.0 \%)$ & \\
\hline Oral anticoagulants & $362(30.7 \%)$ & $18(47.4 \%)$ & \\
\hline $\mathrm{CHA}_{2} \mathrm{DS}_{2}-\mathrm{VASC} \geq 2$ & & & $0.030^{*}$ \\
\hline None & $550(17.5 \%)$ & $72(13.7 \%)$ & \\
\hline Anti-platelet agents & $13(0.4 \%)$ & $0(0.0 \%)$ & \\
\hline Oral anticoagulants & $2578(82.1 \%)$ & $453(86.3 \%)$ & \\
\hline
\end{tabular}

$A C E i$ angiotensin-converting enzyme inhibitor, $A F$ atrial fibrillation, $A R B$ angiotensin receptor blocker, Non-DHP CCB non-dihydropyridine calcium channel blocker

Categorical variables are represented as the absolute value with the percentage in parentheses. Fisher's exact test $\left(^{*}\right)$

frequent. Stroke prevention was relatively well undertaken in AF patients with HF (86.3 vs. $82.1 \%, p=0.030)$.

\section{Symptom burden in AF with concomitant HF}

Among AF patients with HF, 220 (39.1\%, Additional file 1: Table S2) were symptomatic (EHRA class 2-4). The frequency of symptomatic AF was highest in AF patients with HFrEF (47.8\%), but the difference was not significant after adjustment (Fig. 1a). AF patients with HFmrEF and HFrEF had a significantly higher frequency of severe symptoms (EHRA class 3 or 4, Fig. 1b) compared with AF patients without HF, but the presence of HF was not associated with the number of symptoms (Fig. 1c). In symptomatic AF cases, atypical symptoms were more frequently reported by AF patients with HFpEF and HFrEF (Fig. 1d). Among the types of symptoms observed (Additional file 1: Table S2), palpitations were the most common symptom in AF without HF, and shortness of breath was the most common symptom in AF with HF.

Table 3 shows the different factors related to the presence of symptoms in AF according to the presence of HF. Increased HR ( $\geq 100 \mathrm{bpm}$ ) was significantly associated with the presence of symptoms in both groups. However, whereas female sex and AF pattern were determinant factors in AF without HF, non-maintenance of sinus rhythm and increased $E / e^{\prime}$ ratio $(\geq 15)$ were more strongly correlated factors in AF with HF.

\section{Discussion}

Our study demonstrates that AF patients with HF had a frequency of symptoms similar to that of AF patients without HF. However, symptom presentation was more severe and more commonly atypical in patients with HF than in those without it. Factors related to the presence of symptoms also differed according to the presence or absence of HF. Female sex and the type of AF were associated with the presence of symptoms in AF patients without HF. In AF patients with HF, maintenance of the sinus rhythm and a low $E / e^{\prime}$ ratio were closely correlated with the absence of symptoms.

In this study, the presence of HF did not influence the frequency of symptoms. It seems that AF patients with HF had factors associated with asymptomatic presentations, such as a history of diabetes and myocardial infarction $[11,12]$. In addition, more than half the subjects in the present study were asymptomatic, regardless of their degree of LV dysfunction, perhaps because our study population had a relatively high ratio of males. In systematic reviews, the percentage of males was higher among patients with asymptomatic AF than among those with symptomatic AF [13].

Atypical symptoms in AF patients could not be differentiated from the symptoms of other cardiovascular diseases. Most notably, AF and HF frequently coexisted [3]. Therefore, when evaluating the symptoms of AF patients with $\mathrm{HF}$, it is difficult to discriminate whether their symptoms result from AF, HF, or both. Based on our results, the presence of HF appears to be associated with atypical presentation of AF, regardless of the degree of LV dysfunction. Among the various atypical symptoms, 
shortness of breath was the most common in AF patients with HF. Shortness of breath was also frequently present in patients with only HF, but that could not be considered separately from AF. Kaye et al. [14] showed that AF influences the central hemodynamic and peripheral oxygen kinetics in HF. They explained that HF patients with AF had increased filling pressures and lower cardiac output indices despite having similar resting $\mathrm{HR}$ and that such patients exhibited a reduced capacity to increase their oxygen consumption and had relatively impaired cardiac indices during exercise compared with HF patients with sinus rhythm. Therefore, although shortness of breath can originate from HF itself, it can also be caused or aggravated by AF, regardless of the degree of LV dysfunction. Palpitations are considered to be the hallmark AF symptom, but the typical presentation including palpitations might be less common than the asymptomatic or atypical presentation in clinical situations [1]. In this study, palpitations were the most frequent symptom, but they occurred in only one-fifth of patients (Additional file 1: Table S2). However, palpitations were the most common symptom in AF patients without HF. Although atypical symptoms are characteristic of AF patients with HF, palpitations were still the next most common symptom in this study.

A previous study showed that patients with atypical symptoms had higher rates of stroke and mortality than patients with typical symptom presentation [1] Patients with atypical symptoms had significantly higher $\mathrm{CHA}_{2} \mathrm{DS}_{2}$-VASc scores and lower estimated glomerular filtration rates, and they were more likely to have a prior history of diabetes and congestive HF [1]. Our study also shows that AF patients with HF had atypical symptoms more frequently than AF patients without HF, which

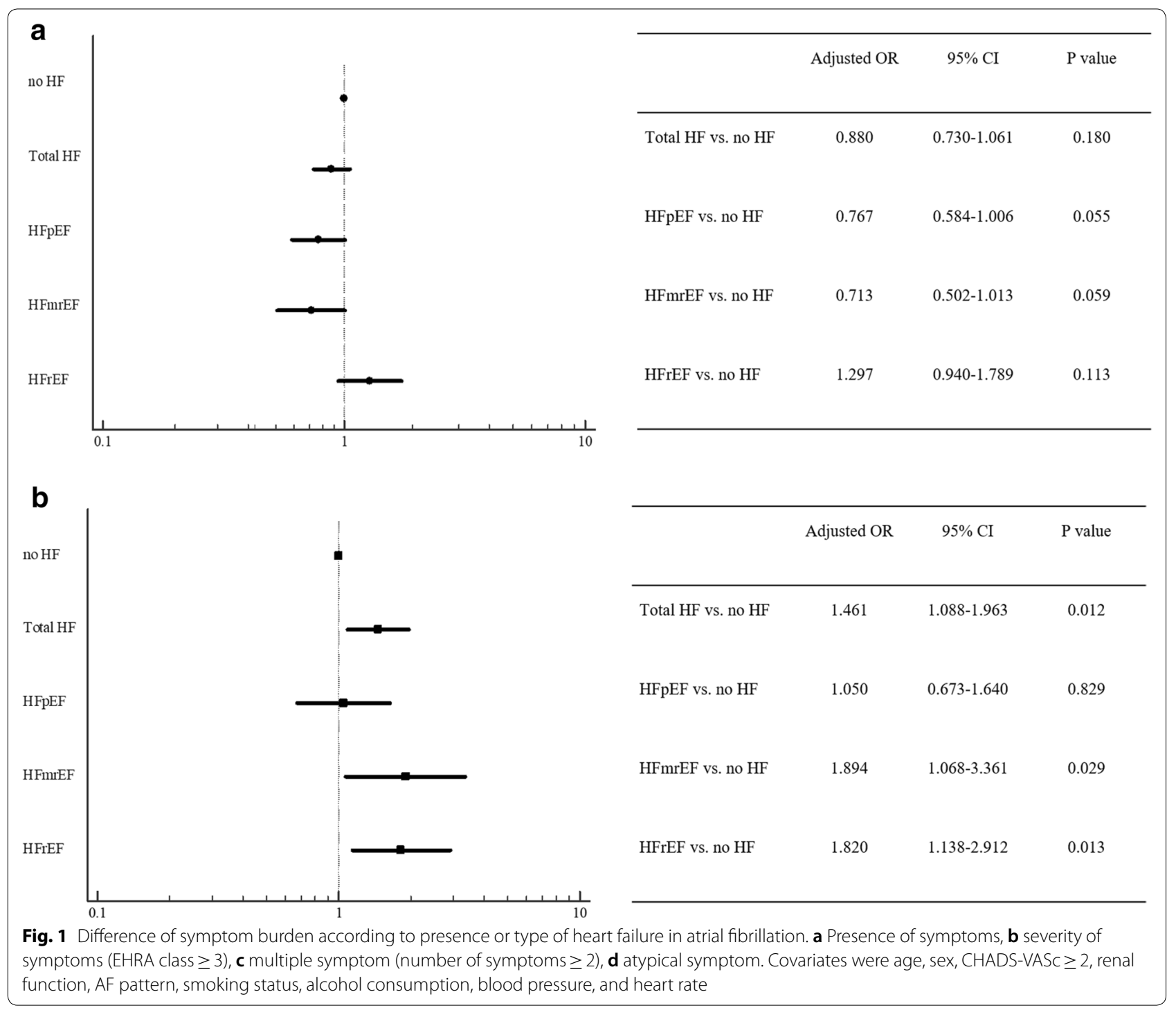




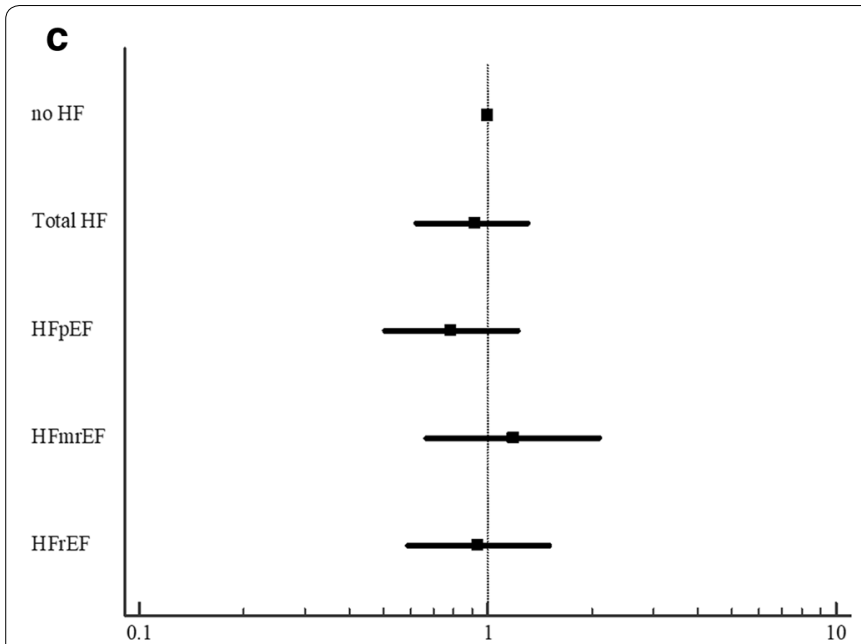

\begin{tabular}{lccc}
\hline & Adjusted OR & $95 \% \mathrm{CI}$ & P value \\
& & & \\
\hline Total HF vs. no HF & 0.920 & $0.623-1.307$ & 0.587 \\
HFpEF vs. no HF & 0.786 & $0.506-1.222$ & 0.286 \\
HFmrEF vs. no HF & 1.181 & $0.667-2.092$ & 0.568 \\
HFrEF vs. no HF & 0.940 & $0.588-1.502$ & 0.795 \\
& & & \\
\hline
\end{tabular}

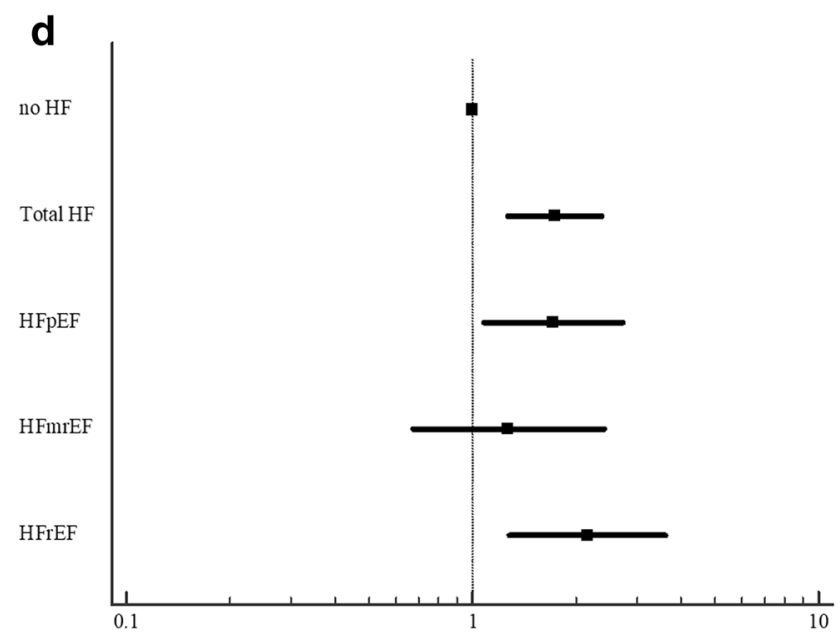

\begin{tabular}{lccc}
\hline & Adjusted OR & $95 \% \mathrm{CI}$ & P value \\
& & & \\
\hline Total HF vs. no HF & 1.732 & $1.266-2.369$ & 0.001 \\
& & & \\
HFpEF vs. no HF & 1.716 & $1.080-2.727$ & 0.022 \\
& & & \\
HFmrEF vs. no HF & 1.270 & $0.670-2.406$ & 0.464 \\
& & & 0.003 \\
HFrEF vs. no HF & 2.142 & $1.273-3.605$ & \\
\hline
\end{tabular}

Fig. 1 continued

suggests that the presence of HF might influence the likelihood of unfavorable cardiovascular outcomes in AF patients with atypical symptoms. In a previous study, AF patients with typical symptoms had a generally lower-risk profile, but patients with atypical symptoms were not significantly more likely to suffer cardiovascular mortality after adjustment for $\mathrm{CHA}_{2} \mathrm{DS}_{2}$-VASc scores [1].

Treatment of AF consists of reducing the arrhythmiaassociated symptoms and preventing ischemic stroke. To reduce arrhythmia-associated symptoms, more than $50 \%$ of AF patients with HF were treated only with rate control medication. In addition to rhythm control, rate control might be important in reducing the symptoms in patients with AF. In data from the EORP-AF Pilot Registry, the HR of asymptomatic patients was about 20 beats/ min lower than that in symptomatic patients [15]. In our study, a HR of more than $100 \mathrm{bpm}$ was a significant factor for the presence of symptoms in AF patients both with and without HF. However, rate control had a limited ability to reduce AF symptoms. Standard guidelines recommend a rhythm control strategy for patients with symptomatic AF [9], and radiofrequency catheter ablation is effective in reducing symptom burden and improving quality of life [15]. A meta-analysis suggested that a rhythm control strategy was superior to rate control in AF combined with $\mathrm{HF}$ and that catheter ablation was more effective in reversing cardiac remodeling than antiarrhythmic medication [16]. The presence of LV systolic dysfunction caused no significant differences in arrhythmia-free recurrence and symptom improvement [6]. However, a rhythm control strategy seems not to have been appropriately applied to AF patients with HF in our cohort. Compared with the degree of symptom burden, AF patients with concomitant HF were less likely than those without HF to be treated with antiarrhythmic drugs or catheter ablation. A previous study using 
Table 3 Deterministic factors related to symptoms according to the presence of heart failure in atrial fibrillation

\begin{tabular}{|c|c|c|c|c|}
\hline & \multicolumn{2}{|l|}{ No HF } & \multicolumn{2}{|l|}{ HF } \\
\hline & Adjusted OR (95\% Cl) & $p$ value & Adjusted OR $(95 \% \mathrm{CI})$ & $p$ value \\
\hline Age $\geq 65$ years & Not selected & & Not selected & \\
\hline Female & $1.52(1.33-1.73)$ & $<0.001$ & Not selected & \\
\hline $\mathrm{BMI} \geq 25 \mathrm{~kg} / \mathrm{m}^{2}$ & Not selected & & Not selected & \\
\hline CHADS-VASC $\geq 2$ & Not selected & & Not selected & \\
\hline PAF versus PmAF & $2.18(1.42-3.35)$ & $<0.001$ & Not selected & \\
\hline PeAF versus PmAF & $1.75(1.13-2.72)$ & 0.013 & Not selected & \\
\hline Heart rate $\geq 100 \mathrm{bpm}$ & $1.54(1.18-2.01)$ & 0.001 & $1.92(1.07-3.43)$ & 0.028 \\
\hline Sinus rhythm at ECG & Not selected & & $0.64(0.43-0.97)$ & 0.033 \\
\hline QRS duration $\geq 120 \mathrm{~ms}$ & Not selected & & Not selected & \\
\hline QTc interval $\geq 480 \mathrm{~ms}$ & Not selected & & Not selected & \\
\hline HFmrEF versus HFpEF & Not applicable & & Not selected & \\
\hline HFrEF versus HFpEF & Not applicable & & Not selected & \\
\hline LA size $\geq 40 \mathrm{~mm}$ & Not selected & & Not selected & \\
\hline$E / e^{\prime}$ ratio $\geq 15$ & Not selected & & $1.47(1.01-2.16)$ & 0.047 \\
\hline
\end{tabular}

Covariates were age $\geq 65$ years, sex, body mass index $(\mathrm{BMI}) \geq 25 \mathrm{~kg} / \mathrm{m}^{2}, \mathrm{CHADS}-\mathrm{VASc} \geq 2, \mathrm{AF}$ pattern, heart rate $\geq 100$ bpm, and parameters of echocardiography and electrocardiography

$B M I$ body mass index, $C l$ confidence interval, ECG electrocardiography, EF ejection fraction, $H F$ heart failure, $L A$ left atrium, OR odds ratio, $Q T C$ corrected $Q T, P A F$ paroxysmal atrial fibrillation, $P e A F$ persistent atrial fibrillation, $P m A F$ permanent atrial fibrillation

registry data for AF showed that only palpitations predicted the use of interventions to restore sinus rhythm [17]. Because atypical symptoms are more common in AF patients with HF and severe symptoms are associated with cardiovascular outcomes [18], rhythm control strategies need to be encouraged. Our study shows that sinus rhythm is an important factor among the less frequent symptoms.

\section{Study limitations}

This study has several limitations. Because all patients were enrolled from tertiary centers, asymptomatic patients with AF might have been less likely to be included in our cohort. Thus, the current registry is not free of referral bias, and the clinical picture shown by these patients might not be generalizable to the whole population. Additionally, symptom status was assessed at the time of enrollment rather than the time of AF diagnosis. Questionnaires about symptom burden and echocardiographic data were not collected simultaneously. However, we analyzed the most recent echocardiographic data based on the time of enrollment to reduce bias. Antiarrhythmic medication and catheter ablation that patients had already undergone could have influenced the presence or degree of symptoms. A few HF patients with preserved EF who had not yet been diagnosed might have been included in the group without HF.

\section{Conclusion}

AF with concomitant HF has a significantly different characteristic symptom burden than AF without HF. The presence of HF mainly affected the severity of symptoms and atypical presentation rather than the mere existence of symptoms. Modifiable factors, such as maintaining the sinus rhythm and a low $E / e^{\prime}$ ratio, were strongly associated with the asymptomatic AF in patients with concomitant HF. These findings could encourage physicians to choose an appropriate treatment strategy for AF patients with HF.

\section{Supplementary information}

Supplementary information accompanies this paper at https://doi. org/10.1186/s42444-019-0009-9.

Additional file 1. Table S1. General characteristics according to the type of heart failure in atrial fibrillation. Table S2. EHRA score and rank of symptoms in atrial fibrillation with and without heart failure.

\section{Abbreviations}

ACEi: angiotensin-converting enzyme inhibitor; AF: atrial fibrillation; ARB: angiotensin receptor blocker; BMl: body mass index; BP: blood pressure; CKD: chronic kidney disease; CODE-AF: Comparison Study of Drugs for Symptom Control and Complication Prevention of AF; ECG: electrocardiography; EF: ejection fraction; EHRA: European Heart Rhythm Association; ESRD: end-stage renal disease; HF: heart failure; HFpEF: heart failure with preserved ejection fraction; HFmrEF: heart failure with mid-range ejection fraction; HFrEF: heart failure with reduced ejection fraction; HR: heart rate; ICD: implantable cardiac defibrillator; LA: left atrium; LV: left ventricle; Non-DHP CCB: non-dihydropyridine calcium channel blocker; PAD: peripheral artery disease; PAF: paroxysmal 
atrial fibrillation; PeAF: persistent atrial fibrillation; PmAF: permanent atrial fibrillation.

\section{Acknowledgements}

The authors thank the Biostatistical Consulting and Research Lab, Hanyang University, for assistance with statistical analysis.

\section{Authors' contributions}

J-KP contributed to the idea and design of this study; J-KP and RH prepared and checked clinical coding and undertook the data analysis; $\mathrm{RH}, \mathrm{M}-\mathrm{JC}$, and J-KP wrote the draft; T-HK, JML, JP, HWP, K-WK, JS, J-SU, JK, J-BK, CK, YSL, and E-KC contributed to data collection and analysis; and J-KP and BJ revised the manuscript; all authors have seen and approved the final version of the report.

\section{Funding}

This study was supported by a grant from the Korean Healthcare Technology R\&D project funded by the Ministry of Health and Welfare ( $115 \mathrm{C} 1200)$ and by the Basic Science Research Program through the National Research Foundation of Korea (NRF) funded by the Ministry of Science, ICT and Future Planning (NRF-2017R1E1A1A01078382, NRF- 2019R1F1A1046443).

\section{Availability of supporting data}

The datasets generated during and/or analyzed during the current study are available from the corresponding author on reasonable request.

\section{Ethical approval and consent to participate}

The study was approved by the ethics committee of each center, and all patients provided informed consent for their inclusion.

\section{Consent for publication}

Applicable.

\section{Competing interests}

The authors declare no conflicts of interest.

\begin{abstract}
Author details
${ }^{1}$ Department of Cardiology, Hanyang University Medical Center, Hanyang University Seoul Hospital, 222-1 Wangsimri Road, Seongdong-gu, Seoul 04763, Republic of Korea. ${ }^{2}$ Department of Internal Medicine, Seoul National University Hospital, Seoul, Republic of Korea. ${ }^{3}$ Division of Cardiology, Department of Internal Medicine, Severance Cardiovascular Hospital, Yonsei University College of Medicine, Seoul, Republic of Korea. ${ }^{4}$ Division of Cardiology, Department of Internal Medicine, Kyung Hee University Hospital, Kyung Hee University, Seoul, Republic of Korea. ${ }^{5}$ Department of Cardiology, School of Medicine, Ewha Womans University, Seoul, Republic of Korea. ${ }^{6}$ Department of Cardiology, Chonnam National University Hospital, Chonnam National University School of Medicine, Gwangju, Republic of Korea. ${ }^{7}$ Division of Cardiology, Eulji University Hospital, Daejeon, Republic of Korea. ${ }^{8}$ Division of Cardiology, Department of Internal Medicine, Korea University Medical Center, Seoul, Republic of Korea. ${ }^{9}$ Heart Institute, Asan Medical Center, University of Ulsan College of Medicine, Seoul, Republic of Korea. ${ }^{10}$ Department of Preventive Medicine, Institute of Human Complexity and Systems Science, Yonsei University College of Medicine, Seoul, Korea. ${ }^{11}$ Division of Cardiology, Department of Internal Medicine, Daegu Catholic University Medical Center, Daegu, Republic of Korea.
\end{abstract}

Received: 3 October 2019 Accepted: 26 November 2019

Published online: 09 January 2020

\section{References}

1. Siontis KC, Gersh BJ, Killian JM, Noseworthy PA, McCabe P, Weston SA, Roger VL, Chamberlain AM. Typical, atypical, and asymptomatic presentations of new-onset atrial fibrillation in the community: characteristics and prognostic implications. Heart Rhythm. 2016;13:1418-24.

2. Freeman JV, Simon DN, Go AS, Spertus J, Fonarow GC, Gersh BJ, Hylek EM, Kowey PR, Mahaffey KW, LE Thomas. Association between atrial fibrillation symptoms, quality of life, and patient outcomes: results from the Outcomes Registry for Better Informed Treatment of Atrial Fibrillation (ORBIT-AF). Circ Cardiovasc Qual Outcomes. 2015;8:393-402.
3. Santhanakrishnan R, Wang N, Larson MG, Magnani JW, McManus DD, Lubitz SA, Ellinor PT, Cheng S, Vasan RS, Lee DS. Atrial fibrillation begets heart failure and vice versa: temporal associations and differences in preserved versus reduced ejection fraction. Circulation. 2016;133:484-92.

4. Calkins H, Hindricks G, Cappato R, Kim Y-H, Saad EB, Aguinaga L, Akar JG, Badhwar V, Brugada J, Camm J. 2017 HRS/EHRA/ECAS/APHRS/SOLAECE expert consensus statement on catheter and surgical ablation of atrial fibrillation. Ep Europace. 2017;20:e1-160.

5. Marrouche NF, Brachmann J, Andresen D, Siebels J, Boersma L, Jordaens L, Merkely B, Pokushalov E, Sanders P, Proff J. Catheter ablation for atrial fibrillation with heart failure. N Engl J Med. 2018;378:417-27.

6. Black-Maier E, Ren X, Steinberg BA, Green CL, Barnett AS, Rosa NS, Al-Khatib SM, Atwater BD, Daubert JP, Frazier-Mills C. Catheter ablation of atrial fibrillation in patients with heart failure and preserved ejection fraction. Heart Rhythm. 2018;15:651-7.

7. Kim H, Kim T-H, Cha M-J, Lee JM, Park J, Park J-K, Kang K-W, Shim J, Uhm $J$-S, Kim J. A prospective survey of atrial fibrillation management for realworld guideline adherence: COmparison study of Drugs for symptom control and complication prEvention of Atrial Fibrillation (CODE-AF) Registry. Korean Circ J. 2017;47:877-87.

8. van der Meer P, Gaggin HK, Dec GW. ACC/AHA versus ESC guidelines on heart failure: JACC guideline comparison. J Am Coll Cardiol. 2019;73:2756-68

9. Kirchhof P, Benussi S, Kotecha D, Ahlsson A, Atar D, Casadei B, Castella M, Diener H-C, Heidbuchel H, Hendriks J, Hindricks G, Manolis AS, Oldgren J, Popescu BA, Schotten U, Van Putte B, Vardas P, Group ESD. 2016 ESC Guidelines for the management of atrial fibrillation developed in collaboration with EACTS. European Heart Journal. 2016;37:2893-962.

10. Lang RM, Badano LP, Mor-Avi V, Afilalo J, Armstrong A, Ernande L, Flachskampf FA, Foster E, Goldstein SA, Kuznetsova T, Lancellotti P, Muraru D, Picard MH, Rietzschel ER, Rudski L, Spencer KT, Tsang W, Voigt JU. Recommendations for cardiac chamber quantification by echocardiography in adults: an update from the American Society of Echocardiography and the European Association of Cardiovascular Imaging. Eur Heart J Cardiovasc Imaging. 2015;16:233-70.

11. Boriani G, Laroche C, Diemberger I, Fantecchi E, Popescu MI, Rasmussen LH, Sinagra G, Petrescu L, Tavazzi L, Maggioni AP, Lip GY. Asymptomatic atrial fibrillation: clinical correlates, management, and outcomes in the EORP-AF Pilot General Registry. Am J Med. 2015;128(509-18):e2.

12. Potpara TS, Polovina MM, Marinkovic JM, Lip GY. A comparison of clinical characteristics and long-term prognosis in asymptomatic and symptomatic patients with first-diagnosed atrial fibrillation: the Belgrade Atrial Fibrillation Study. Int J Cardiol. 2013;168:4744-9.

13. Xiong Q, Proietti M, Senoo K, Lip GY. Asymptomatic versus symptomatic atrial fibrillation: a systematic review of age/gender differences and cardiovascular outcomes. Int J Cardiol. 2015;191:172-7.

14. Kaye DM, Silvestry FE, Gustafsson F, Cleland JG, van Veldhuisen DJ, Ponikowski P, Komtebedde J, Nanayakkara S, Burkhoff D, Shah SJ. Impact of atrial fibrillation on rest and exercise haemodynamics in heart failure with mid-range and preserved ejection fraction. Eur J Heart Fail. 2017;19:1690-7.

15. Walfridsson $H$, Walfridsson $U$, Nielsen JC, Johannessen A, Raatikainen $P$, Janzon M, Levin L, Aronsson M, Hindricks G, Kongstad O. Radiofrequency ablation as initial therapy in paroxysmal atrial fibrillation: results on health-related quality of life and symptom burden. The MANTRA-PAF trial. Ep Europace. 2015;17:215-21.

16. Ahn J, Kim HJ, Choe JC, Park JS, Lee HW, Oh JH, Choi JH, Lee HC, Cha KS, Hong TJ, Kim YH. Treatment strategies for atrial fibrillation with left ventricular systolic dysfunction- meta-analysis. Circ J Off J Jpn Circ Soc. 2018;82:1770-7.

17. Schnabel RB, Pecen L, Rzayeva N, Lucerna M, Purmah Y, Ojeda FM, De Caterina $R$, Kirchhof P. Symptom burden of atrial fibrillation and its relation to interventions and outcome in Europe. J Am Heart Assoc. 2018;7:e007559.

18. Vermond RA, Crijns HJ, Tijssen JG, Alings AM, Van den Berg MP, Hillege HL, Van Veldhuisen DJ, Van Gelder IC, Rienstra M. Symptom severity is associated with cardiovascular outcome in patients with permanent atrial fibrillation in the RACE II study. Europace. 2014;16:1417-25.

\section{Publisher's Note}

Springer Nature remains neutral with regard to jurisdictional claims in published maps and institutional affiliations. 